DOI: http://doi.org/10.52716/jprs.v11i2.499

\title{
Determination of the Northwestern Extensions of the Bai Hassan Field (Daoud Culmination) and Its Geological Relationship with Ismail -1 Area, Northern Iraq
}

\author{
Ahmed Ibrahim Saleh Al-Naemi ${ }^{1, *}$, Dr.Torhan Medhir Almufti ${ }^{2}$ \\ ${ }^{1}$ Sinor Chief Geologist / Department of Geology / North Oil Company \\ ${ }^{2}$ Expert in the Iraqi consultative office, Baghdad. \\ 1,* Corresponding Author E-mail: Ahmedalnaemi330@gmail.com \\ 2E-mail: muftitorhan@yahoo.com,
}

Received 11/11/2020, Accepted 19/1/2021, Published 20/6/2021

This work is licensed under a Creative Commons Attribution 4.0 International License.

\section{$\underline{\text { Abstract }}$}

The Ismail-1 is located northwest of the Bai Hassan Field (Daoud Culmination), within the administrative boundaries of the provinces of Kirkuk and Erbil, which was later named Ismail Field. The objective of the research is to determine the geological relationship (structural and reservoir) of the well Ismail-1 with the Bai Hassan Field (Daoud Culmination). Based on geological and reservoir studies and seismic surveys of the region, the first basis of the research was based on the stratigraphy, structural, reservoir and morph structure aspects of this relationship.

In the beginning, the serial sequence of the well was reviewed and compared with David's wells. Then, cross-sections and long sections were drawn through the wells of Ismail-1 and Daoud wells, as well as, the fluid levels dotted on such sections. After that, a structural contour map was drawn on top of Jeribe Formation for the area of well Ismail-1 which is currently known as Ismail Field and part of the Bai Hassan Field (Daoud Culmination), depending on the structural and reservoir data. It was found that the area of the well Ismail-1 is an asymmetrical convex fold, the southwestern flank is more inclined than the northeastern flank, and the Daoud Culmination and the Ismail 
fold is separated by a narrow saddle. However, depending on the structural contour map of the top of Jeribe Formation (-1325) meters from the mean sea level, the deeper levels of which surround the two Culminations together, the similarity of the reservoir properties and the different levels of fluid in the Daoud Culmination and the area of the Ismail-1, all confirm that they are two separate Culminations of one field. So the socalled Ismail Field can be considered a third Culmination called Ismail Culmination of the Bai Hassan Field.

Using topographical maps and satellites data, the morph structure and geomorphological phenomena of the northwestern extensions of the Bai Hassan Field (the area of well Ismail-1) and towards the Quir Field, were studied and the northwestern aerial extensions of about $18 \mathrm{~km}$ length and $5 \mathrm{~km}$ width were delineated.

Thus, the Bai Hassan Field is consisting of three Culminations (from the southeast to the northwest, Kithka, Daoud and Ismail Culminations) with a total length about $50 \mathrm{~km}$.

\section{Introduction}

The Ismail-1 area (Bai Hassan-130 previously) was consider an extension of the Bai Hassan field. The Bai Hassan-130 (Ismail-1) was drilling for the purpose of identifying the northwestern extensions of the Bai Hassan Field [1, 2]. The existence of a structural enclosure in en echelon arrangement with the Dauod Culmination was later called the Ismail structure, which is structurally lowest from Daoud and Kithka Culminations, respectively.

The Bai Hassan Field extends parallel to the Kirkuk Field, with axis direction northwest-southeast. There is a sinisteral strike slip fault separating the Kithka and Daoud Culminations in the Shahal saddle area, where the axis of the structure deviates by 10-30 degrees from the northwest-southeast trend to the west direction [4].

The Bai Hassan field consists of an asymmetrical anticline fold, its southwestern flank is steeper than its northeastern flank, and the field forms two Culminations, 
separated by a shallow saddle called Shahal (Kithka Culmination about 4,4 x $18.5 \mathrm{~km}$ and Daoud Culmination about $17 \times 4 \mathrm{~km}$ ), and their axis extends from northwest towards the southeast. The Daoud Culmination is structurally lowest and smaller than Kithka Culmination about 320 meters at the top of Jeribe Formation, while, the northwest extension of Ismail -1 well area, that located to the northwest from Daoud Culmination within the administrative boundaries of Kirkuk province was later called Ismail Field.

The first exploration well Bai Hassan -1 was drilled in 1929, and the number of wells drilled until the preparation of this research is 198 wells, the Bai Hassan -130 (Ismail -1) well was drilled in1996 about $6 \mathrm{~km}$ far from the Bai Hassan -92.

\section{Tectonic setting of the research area}

The Bai Hassan field and the Ismaili-1 well area are located within the Foothill Zone according to Jassim and Goff, (2006), with long-shaped anticlinal folds trending in northwest-southeast direction, formed by the Alpine orogeny movements that occurred in Late Tertiary.

The structure shape of the Bai Hassan area was the result of two tectonic forces: first the influence of tension forces in the Cretaceous period which formed normal faults with large displacements that caused a graben with top of the Upper Cretaceous succession, then the succession influenced by compressive forces in Tertiary period, forming reverse faults and related folds [4].

\section{Surface Geology of the research area}

The Ismail-1 well area is covered by recent sediments of the quaternary deposits, which are characterized by non-rigid soil and some conglomerates. The Ismail-1 well 
area also has no outcrop of various geological formations [5]. While the Bai Hassan Field is covered with the rocks of the lower Bakhtyari (Mukdadia), Upper Fars (Injana) and Lower Fars (Fatha) Formations at the surface fold.

\section{Geological surveys}

Many gravitation and magnetic surveys were carried out during the 1940s and 1950s, but they covered only specific parts of the Bai Hassan-Quir patch. Painted gravitational remaining map by Brown shows an abnormal gravitational anomaly (75+ Cal million) on the Bai Hassan structure in [6].

\section{Seismic surveys}

1. The first survey carried out in $\mathbf{1 9 5 5}$ by the Iraqi Oil Company, where the results indicated the existence of several closures within the Bai Hassan - Quir area.

2. Magnetic surveys carried out by the French Geophysics Company (1973-1974).

3. Seismic survey of the region of Khormala - Quir - Bai Hassan carried out by the French Geophysics CGG, 1973.

4. Reconnoitering and detailed survey of Kirkuk - Bai Hassan- Khabaz area and interpreted by the Oil Exploration Company, 1986.

\section{Location of the research area}

The Bai Hassan field and the Ismail-1 well are located within operations of the North Oil Company in the Kirkuk governorate, between the Kirkuk Field (the Avanah Culmination) in the northeast and Kara Chuq structure in the southwest, with parallel axes, and separated by a wide syncline. Also, the research area is located between the Khabaz field in the south and Quir structure to the north, Figure (1). 


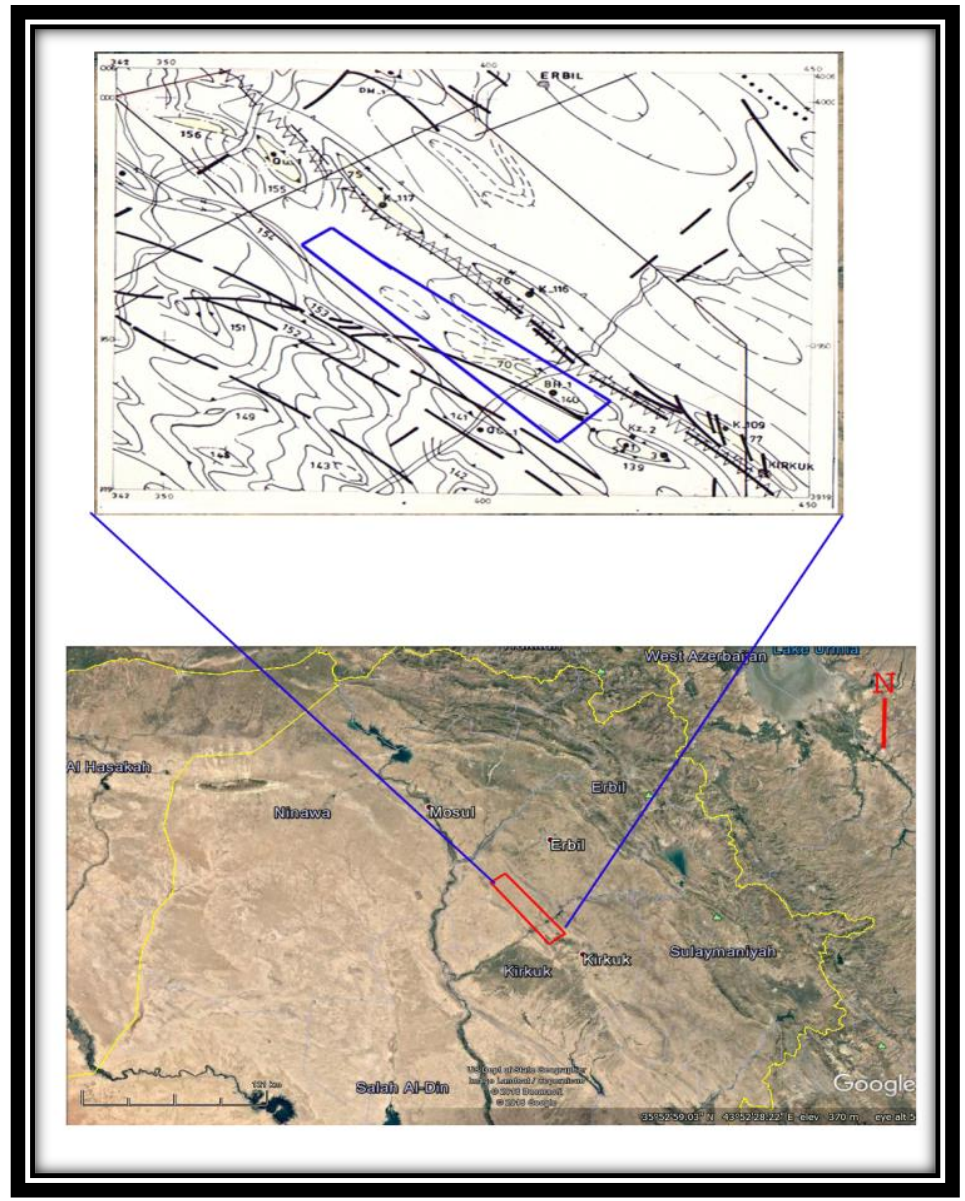

Fig. (1) Location of the research area

\section{Objective of the research}

The objective of the research is to determine the geological, structural, and morph structural relationship of the Ismail -1 well area with the Bai Hassan Field (Daoud Culmination) depending on geological and reservoir studies and previous seismic surveys of the area. 


\section{Structural contour map on top of Jeribe Formation (Kithka and Daoud Culminations) - Bai Hassan Field}

The structure contour map, Figure (2) shows that the structure is an asymmetrical longitudinal fold with dimensions $(32 \times 4.2) \mathrm{Km}$. It extends in southeast - northwest direction. The Daoud Culmination with dimensions $(10.5 \times 4.2) \mathrm{km}$ and Kithka Culmination with dimension $(20 \times 4) \mathrm{km}$ are separated by Amsha saddle. The axis of the Culminations is deflected, which is likely to be affected by the displacement of a strike slip fault. There are two longitudinal faults that cut down the flanks of the structure, causing their flanks to be very steep, in addition to the presence of a reverse fault that cuts the southeastern plunge of the structure. However, there are two normal faults, F 4 and 5 , which cut through the Kithka Culmination, where the Zab River flow through it. The Daoud Culmination is structurally lower than Kithka Culmination about $(320 \mathrm{~m})$ at the top of Jeribe Formation. There is another fault F7 located at the southwest flank of the Daoud Culmination. As well as, the northwest plunge of the fold is oblique to north due to the influence of fault F8. 
Journal of Petroleum Research and Studies

Open Access

No. 31, June 2021, pp.74-85

P- ISSN: 2220-5381

E- ISSN: 2710-1096

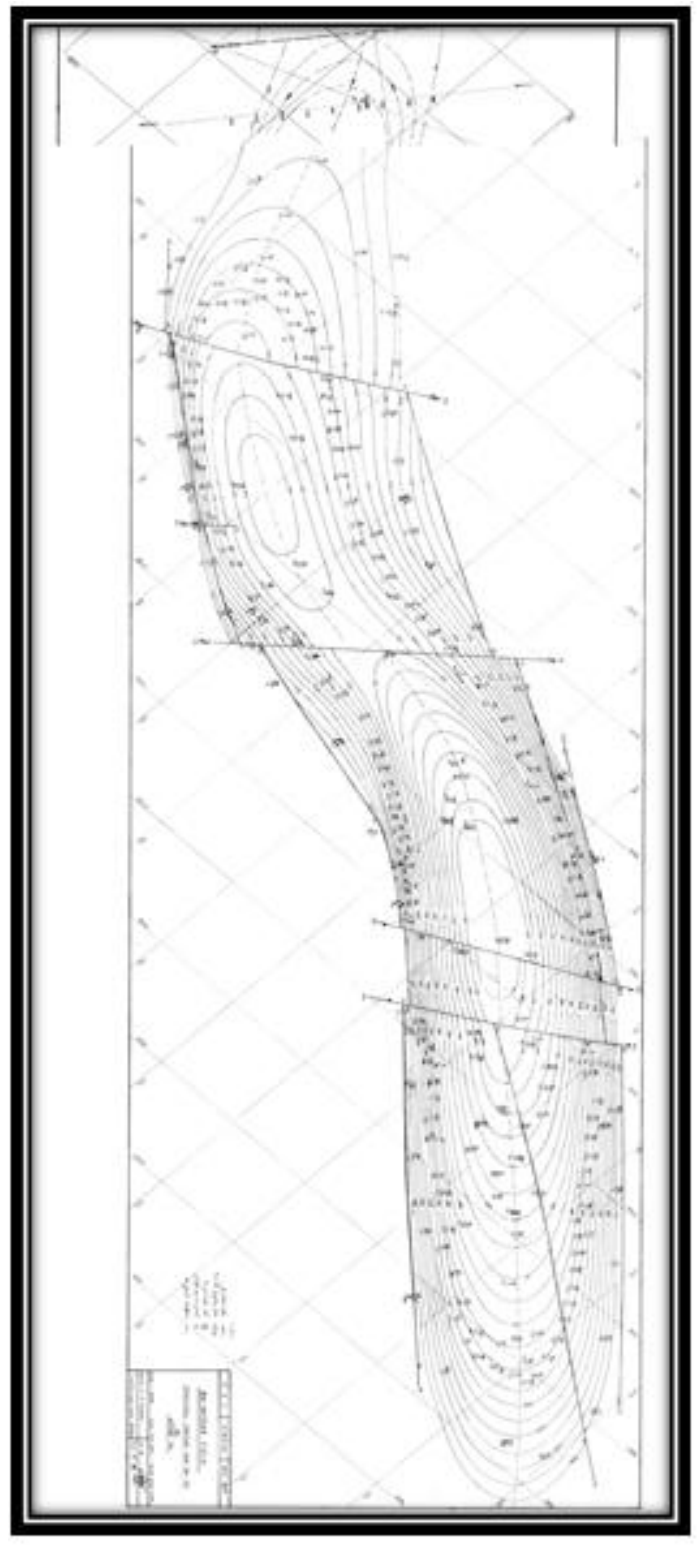

Fig. (2) Structural contour map on top of Jeribe Formation (Kithka and Daoud Culminations) Bai Hassan Field 


\section{Structural contour map on top of Jeribe Formation (Ismail Culmination) Bai Hassan Field}

Figure (3) is another structure contour map showing that the Ismail - 1 area is an asymmetrical longitudinal fold with dimensions about $(10 \times 4.2) \mathrm{Km}$. It extends in southeast - northwest and separated by narrow saddle. The axis of the Culmination is deviated, that is likely to be affected by the displacement of a strike slip fault. The Ismail Culmination is structurally lower than Daoud Culmination about (375 m) at the top of Jeribe Formation.

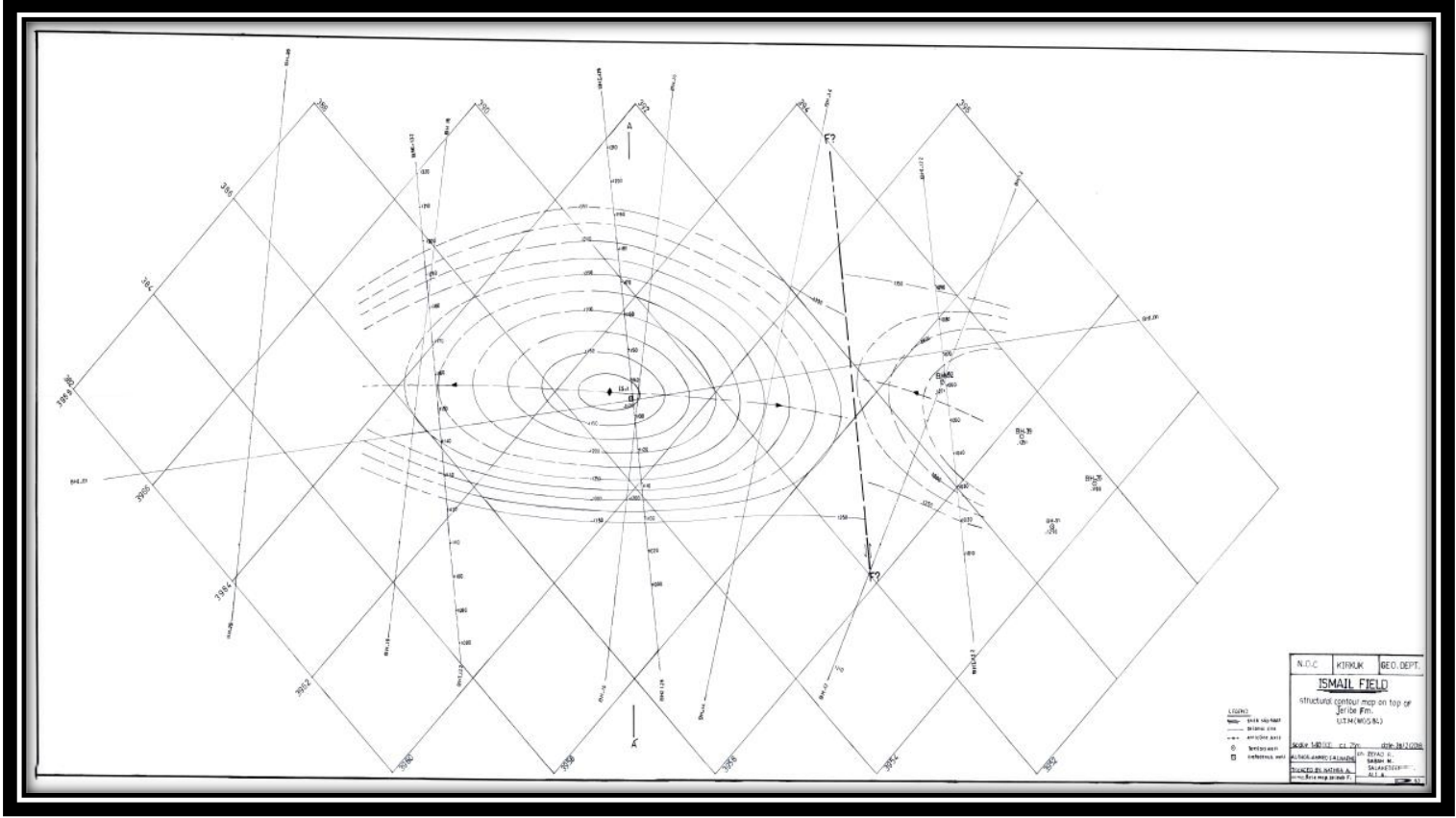

Fig. (3) Structural contour map on top of Jeribe Formation (Ismail Culmination) Bai Hassan Field 


\section{Structural contour map on top of Jeribe Formation (Kithka, Daoud and Ismail Culminations) Bai Hassan Field}

The structural contour map drawn on top of Jeribe Formation for the Ismail -1 well area was compared and linked with the structural contour map on top of Jeribe Formation for (Kithka and Daoud Culminations) Bai Hassan field using modern software (Surfer 11 and Didger 3) Figure (4). It is clear that the two maps are linked together at the contour line -1350 meters from the mean sea level, where the line represents the last closure contour line (-1325) for both Daoud Culmination and Ismail 1 well area, and marking a narrow saddle area in between.

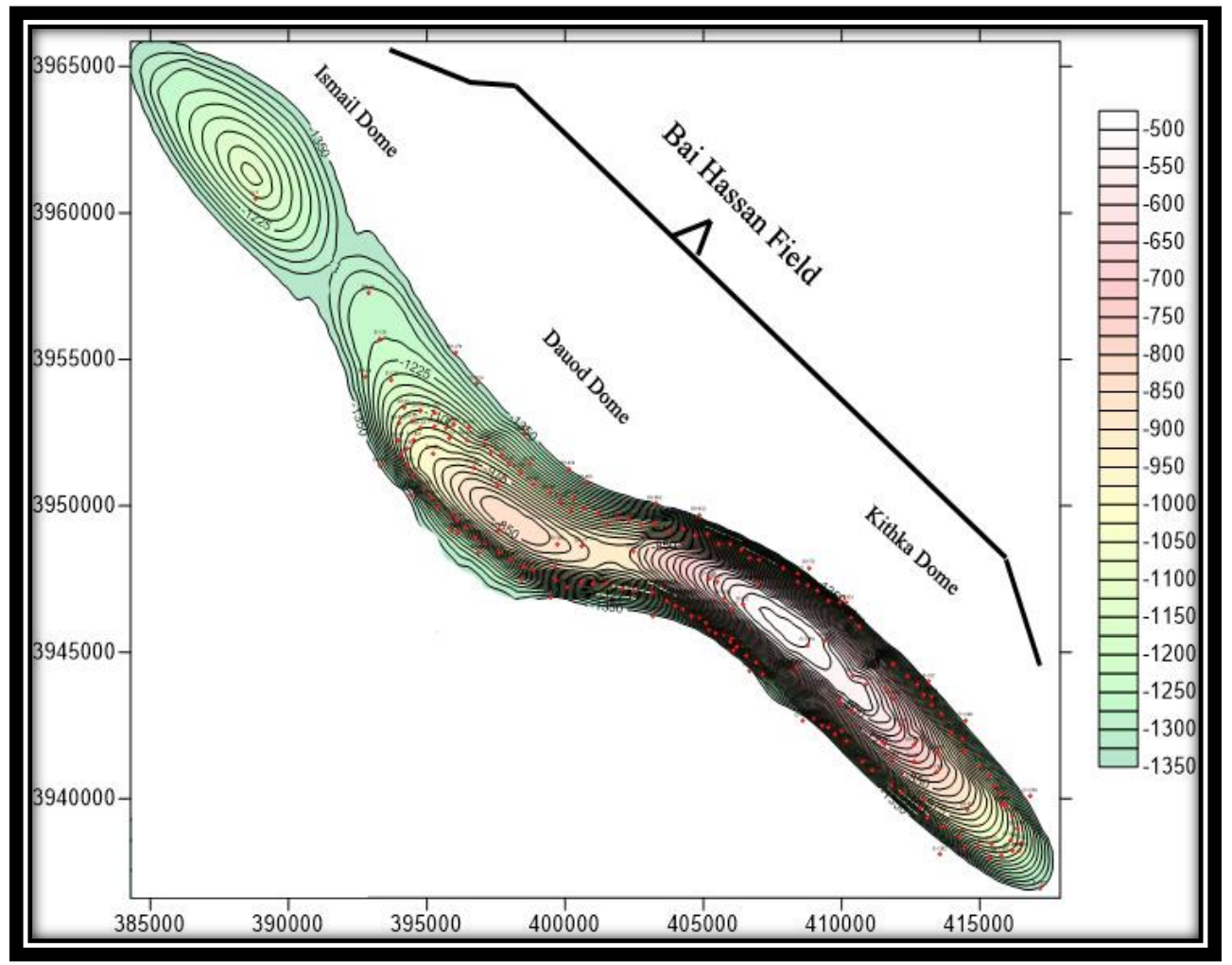

Fig. (4) Structural contour map on top of Jeribe Formation (Kithka, Daoud and Ismail Culminations) Bai Hassan Field 
Open Access

No. 31, June 2021, pp.74-85

\section{Geomorphology of the research area}

The available data from the Landsat 7 satellite were used to map the drainage patterns of study area, Figure (5). It is noted that the main drainage patterns are of radial type stemming from the new Culmination center of the well-Ismail 1 area. The general shape of the drainage patterns is of the dendritic and parallel patterns.

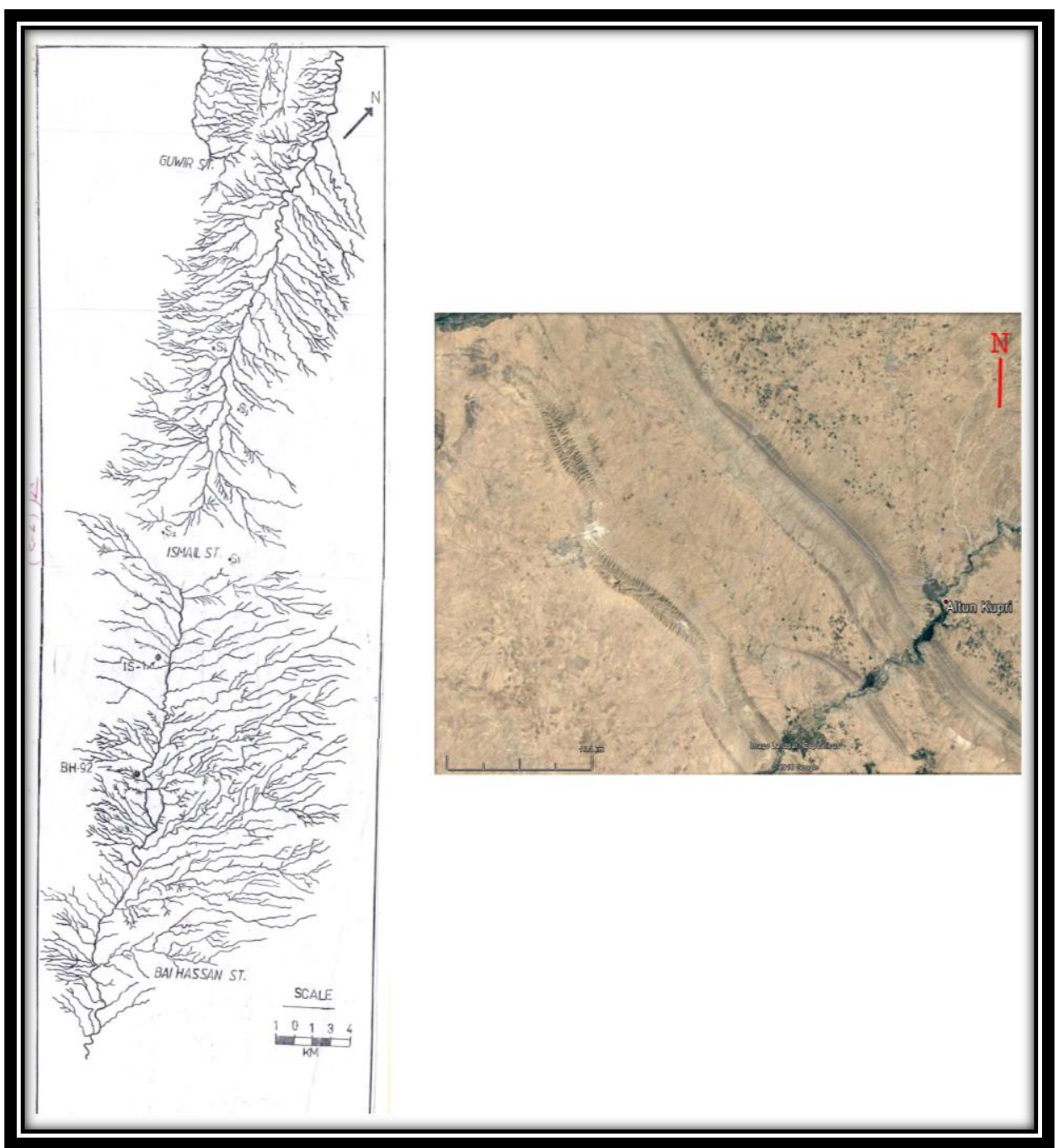

Fig. (5) satellite image and drainage patterns in the research area. 
When the network of drainage patterns was distinguish, it became possible to distinguish between the well Ismail-1 area and the Quir structure to the northwest of it because the Quir structure is clear surface structure and can be traced from the drainage patterns. Whereas it is impossible to distinguish between the well Ismail-1 area and the Daoud Culmination because they are subsurface structures.

\section{The reservoir setting of the research area}

The well Bai Hassan -92 was drilled at the northeast flank in the end of the northwest plunge of Daoud Culmination towards the area of Ismail-1 well, to find the extension of the Daoud Culmination. The well produce oil with water, and it is found that the level of oil / water contact is at the depth (-1338) meters from mean sea level.

After that, a new well site was located approximately $6 \mathrm{~km}$ from the well of Bai Hassan-92 to the northwest and the well (Bai Hassan -130) was drilled also, and it was found that the level of oil / water contact is -1200 meters from mean sea level [7][8]. This gives more extension of Bai Hassan structure towards northwest and adds a new reserve.

\section{Conclusions}

1. The Ismail -1 area is a fold with dimensions about $(18 * 5 \mathrm{~km})$ according to the satellite data.

2. The Ismail -1 area is considered the third Culmination of the Bai Hassan Field linked structurally to the Kithka and Daoud Culminations, so the Bai Hassan Field consists of three Culminations which are from the southeast to northwest (Kithka, Daoud and Ismail) and with the length of about $50 \mathrm{~km}$. 


\section{Journal of Petroleum Research and Studies}

Open Access

No. 31, June 2021, pp.74-85

\section{References}

[1] NOC, Final Well Report for Ismail-1 well, library of geological department, Kirkuk, 1996.

[2] NOC, Final Well Report for BH-92 well, library of geological department, Kirkuk, 1992.

[3] Jassim, S. Z. and Goff, J. C., Geology OF IRAQ, Dolin, Prague and Moravian Museum, Brno, 2006.

[4] شركة نفط الثمال، دراسة جيولوجية لمكامن العصر الثلاثي في حقل باي حسن، ارشيف قسم الجيولوجيا، كركوك، دراسة غير منشورة، 1990.

[5] طور هان مظهر المفتي، دراسة تحديد امتدادات تركيب اسماعيل و علاقته مع التر اكيب المجاورة. ارشيف قسم الجيولوجيا، كركوك، دراسة غير منشورة، 2003.

[6] شركة الاستكشافات النفطية، دراسة تفاسير منطقة كوير كركوك العميق (باى حسن، خباز، كوير) التفصيلي، ارشيف قسم الجيولوجيا، كركوك، دراسة غير منشورة، 1986.

[7] نجيب ونعمة، التقييم الاولي لبئر باي حسن 130، شركة الاستكثافات النفطية، ارشيف قسم الجيولوجيا، كركوك، دراسة غير منشورة، 1997.

[8] قاسم وعروبة، دراسة رسوبية لمكمن بئر اسماعيل شركة الاستكثافات النفطية. ارشيف قسم الجيولوجيا، كركوك، در اسة غير منشورة، 1999. 